\title{
LA INFLUENCIA DE LA MITOLOGÍA CLÁSICA EN LA NARRATIVA BREVE DE MAX AUB
}

\author{
Raquel Benítez Burraco
}

\begin{abstract}
RESUMEN
En este artículo, se analizan las formas en las que se muestra el contenido mitológico en la narrativa breve de Aub, prestando una atención especial a las fuentes clásicas. Aunque en ocasiones se citan estas fuentes como muestra de erudición o adorno literario, en la mayor parte de los casos el mito, como eterno que es, se presenta actualizado en consonancia con las experiencias del autor y el mundo en que le tocó vivir. De manera específica, aparecen personajes mitológicos como Prometeo, Teseo o las sirenas, pero también se encuentran motivos míticos como la Edad de Oro o la metamorfosis aplicados al universo particular de Aub. La naturalidad con la que se incluyen en este universo los motivos citados hace que, en el fondo, el mundo del autor sea él mismo mítico.
\end{abstract}

\begin{abstract}
In this article we analyse how Aub includes mythological material in his short narrative, paying attention to classical sources. Although sometimes he only quotes these sources as an ornament, the mythological story, eternal as it is, is used as a way of understanding the present. This adaptation is presented according with the author's experience and the time (and the society) in which he lived. We can find mythical characters (Prometeo, Teseo, sirens) and mythical situations (Golden Age, metamorphosis) applied to Aub's universe in a very natural way, so, finally, this universe is made mythological itself.
\end{abstract}

\section{Introducción}

Como es habitual en la creación literaria, hay que entender la obra en su contexto vital y sociocultural. Sin embargo, parece que la situación en que se propone un estudio monográfico y concreto aconseja prescindir de la habitual semblanza biográfica que se suele incluir en las introducciones, con el fin de situar al lector en el mundo del autor que se estudia. Sobre Max Aub, sobre todo en los últimos años, se ha escrito mucho y bien, y, por tanto, damos por supuestas las líneas generales que configuran su obra, de manera que las páginas que siguen se puedan centrar en el tema propuesto.

Para el análisis de la influencia de la mitología clásica en Max Aub, teniendo en cuenta que su producción literaria es amplísima y abarca todos los géneros, tanto en forma pura como híbrida, se ha seleccionado una serie de obras dentro de aquellas que corresponden a la 
narrativa, especialmente a la narrativa de ficción, si bien hay que tener en cuenta, como se verá, que ficción e historia se entrelazan de manera inseparable en este autor. Dentro de la narrativa, se han elegido las piezas breves, sin que ello responda más que a un gusto personal de la que esto escribe. Por último, y aunque lo deseable hubiera sido poder revisar, lápiz en mano, toda la producción de esta clase dentro de la obra del autor, problemas prácticos de tipo editorial han hecho que la lista haya quedado reducida a lo indicado en el apartado de referencias bibliográficas consultadas.

Agradezco a los responsables de la Fundación Max Aub el apoyo bibliográfico y, sobre todo, su amabilidad y eficacia.

\section{El mito en la configuración de la obra de Max Aub}

\subsection{El mito en la literatura del 27}

El mito clásico forma parte de la literatura de la Edad de Plata española a través de fuentes diferentes y complementarias.

El simbolismo y la literatura finisecular habían utilizado el mito para reflejar un mundo poético que se alejaba del prosaísmo imperante en la sociedad, y los autores de las primeras décadas del XX heredaron esas tendencias, especialmente en lo que se dio en llamar la "literatura deshumanizada". Además, la aparición de los mitos clásicos como referencia cultural ineludible entre los autores de la Generación del 27, en la que se puede encuadrar a Max Aub, guarda relación, sin duda, con la admiración que estos autores mostraron hacia los clásicos del Siglo de Oro. Aunque también "lo que ocurre es que la generación del 27 ha tenido siempre un carácter receptivo en el que no se excluye nada y absorbe todo aquello que emana de la tradición simbolista. Y visto así, Max Aub se inscribe en la nómina de la generación del 27" (Aub 1998: 27).

Así, no es raro encontrar apariciones de figuras y temas mitológicos en las primeras obras de Aub, en aquellas en las que se adscribe de modo voluntario a esa literatura preciosista y de minorías. Sin embargo, incluso después de optar por el compromiso literario, sigue refiriéndose al mito en general, y al mito clásico en particular, de modo consciente y en ocasiones tal vez inconscientemente, como se verá.

\subsection{El mestizaje mitológico de Max Aub}

La aparición del mito en Max Aub no se circunscribe al clasicismo grecolatino, a pesar de que se ha dicho que "el mundo clásico ha llamado la atención de los autores de procedencia hebrea que, por las razones que sea, no han gozado de la religión de sus padres [y ocurre] así en nuestro autor" (Aub 2001: 14). No parece que esta sea la razón o la fuente única ni principal de las referencias a la mitología clásica en Aub, teniendo en cuenta todo lo que se ha dicho con anterioridad. Además, aunque no es materia de este trabajo, sería muy interesante ver cómo en algunos momentos se mezclan distintas mitologías, incluida la cristiana, que se sitúa, teniendo en cuenta la educación agnóstica del autor, en el mismo nivel de "irrealidad" 
que la clásica. Así, por ejemplo, en Fábula verde, el símbolo de la manzana que la protagonista da a luz y el mundo idílico en el que vive pertenecen a la mitología recogida por el Génesis judeocristiano, que se parodia sin reservas (cfr. Martínez 1996). Sin embargo, también se podría relacionar este tema mítico con el Jardín de las Hespérides y la "manzana de oro", o con la Edad de Oro narrada por los clásicos, con lo que se comprueba el fondo común de ambos mundos. A estas dos líneas mitológicas se suma el sustrato indoamericano con el exilio del autor a México. Este sustrato se presenta mezclado con historias chinas, judeocristianas y clásicas, sin ubicarlas en la historia. Así, en "La verdadera historia de los peces blancos de Pátzcuaro", el mito se manifiesta con su intención original, como explicación de los hechos de la naturaleza:

[Las serpientes] bajaron a los infiernos y consiguieron firmar una alianza indefinida con los señores del fuego, en recuerdo de Tenochtitlán. Y así nacieron, como bastiones naturales alrededor de su lago, los volcanes que hoy se ven (Aub 2001: 183).

Más interesante aún resulta este tipo de referencias en otras historias donde se dan por supuestos los orígenes míticos de la realidad. En "Uba-Opa", se indica entre paréntesis que:

(la anguila es un pez envidioso al que castigaron quitándole las aletas y que desde entonces se arrastra por el fango) (Aub 2001: 137).

Sin embargo, volviendo a la mezcla de mitologías, es en el cuento anteriormente citado donde se observa de modo más claro. Sirva a modo de ejemplo:

Poseidón -el don de poseer- era entonces, todavía, el rey de los temblores. Por eso se llamaba también Enochtithon, el que conmueve la tierra (Aub 2001: 174).

Este "mestizaje mitológico" es viable desde el momento en que, como se ha indicado, las diferentes mitologías presentan paralelismos más o menos acentuados. Además, se adecua perfectamente a una especie de "talante mítico" que podemos llamar "aconfesional" y que impregna la obra de Aub mucho más de lo que aparentemente parece, hasta el punto de que Juan Luis Alborg lo sitúa "en el camino de un inequívoco realismo mágico [aunque a la vez] dentro de lo que denomina un realismo exaltado" (1962: 121-2).

\subsection{El "talante mítico" de Max Aub}

\subsubsection{El mito como configurador de la trayectoria literaria de Max Aub}

Soldevila advierte las raíces míticas de la visión laberíntica del mundo que preside $E l$ laberinto mágico ${ }^{l}$. Con posterioridad, llega más lejos aún y afirma que se puede percibir

una imagen metafórica de la totalidad de la obra de Aub basada en la simbología mitológica, que podríamos dar como entramado o cañamazo a la vez exterior e interno sobre el que parece histórico que ficticio (...) Tras el nuevo examen de los elementos mitográficos en los que se sustenta la visión maxaubiana, creo que son fundamentalmente dos, y que los dos estaban ya presentes en la obra de preguerra, personificados en las figuras de Narciso y Teseo. Estos simbolizarían -en una polarización antagónica- a los campeones de un singular combate por el predominio en la orientación de su obra literaria (1996: 44). 
Aunque con posterioridad se presentará la aparición de estas figuras mitológicas, hay que entender esta afirmación como la presencia de dos tendencias de tipo general, semejantes (salvando las distancias) a las tendencias apolíneas y dionisíacas que conforman el arte de Occidente. Por tanto, tal vez no sea una característica exclusiva de la narrativa de Max Aub. La encarnación en figuras míticas de estas dos tendencias puede verse, pues, como recurso metafórico de la crítica más que como influencia de los mitos clásicos en el autor. Si lo que se está planteando es que en general los personajes se orientan hacia la autocontemplación o la acción, esto es compatible con todo lo que se ha dicho de modo amplio sobre la obra de Aub y del 27 en general, ya que oscila entre el juego y el compromiso, normalmente pasando de lo primero a lo segundo.

El propio Soldevila advierte que no estamos ante mera erudición:

\begin{abstract}
No estamos sólo pensando, con ser verdad, que la formación clásica de Aub sea manantial de estas figuraciones, sino que la mitología encierra en su memoria ancestral los grandes y casi siempre recurrentes problemas de la condición humana, y que la aventura personal y espiritual en la que cada uno se conforma, encuentra, por poco que escarbe en esa fuente de los mitos, materia idónea sobre la que retejer una interminable y por necesidad inacabada historia en la que el creador se ve y se reconoce (1996: 45).
\end{abstract}

Se desarrollará esta idea en el apartado siguiente.

Ni siquiera en lo que hemos adscrito a la "literatura deshumanizada", de vanguardia, la aparición del mito clásico puede considerarse puro artificio. Aunque sirva para dotar al texto "de plurivalencias que enriquecen y complican su significado" (Martínez 1996: 399), lo cierto es que también supone "parte de la visión perspectivística de la realidad adoptada por el escritor vanguardista” (399). Y la pluralidad de perspectivas no responde sólo a un despliegue de erudición, sino a una manera de ver el mundo que inaugura la Modernidad (dando lugar, por ejemplo, al cubismo en pintura).

El gusto por los desdoblamientos y el juego entre narrador, autor y personaje, historia y ficción, que se manifiesta de forma más evidente en Luis Álvarez Petreña y Antología traducida, nos hace ver al autor como un ser proteico. De hecho, Aub hace suyas las palabras de Heine: "Cuando el poeta imagina su doble, observador sin entrañas, le [sic] refleja, avalora y abre otros caminos. Lo había visto perfectamente Gerardo de Nerval: "Es el hombre de los contrarios (...) Jamás Proteo tomó más formas"” (en Aub 1998: 58). Para López Casanova (1996: 630), este carácter dialéctico o proteico es la característica principal de la poética de Aub. También se corresponde con el uso de máscaras o "personae", cuyo origen es clásico (cfr. Carreño 1996; Irizarry 1979). Y esto va a ser una constante en toda la obra del autor.

El mito, además, como explicación que es de aquello para lo que no se encuentra causa racional, es una forma de reinventar la realidad y sirve para cambiarla, del mismo modo que sirven la ironía y el humor, como argumenta Manuel Durán:

\footnotetext{
Si a Max no le agradaba la historia, el tiempo histórico que le tocó vivir, no le quedaba otro remedio que tratar de cambiarlo, renovar y cambiar una historia que había matado a tanta gente, entre ellos pintores y escritores, y para ello era preciso crear, como compensación, gente nueva, inédita, gente mucho más manejable que los personajes de veras vivos (1996: 133).
}

El uso del mito podría considerarse otra estrategia para conseguir el mismo fin. 


\subsubsection{La mitología "personal” de Max Aub}

Al mismo tiempo, incluso en las obras en las que no hay referencia a los mitos clásicos, como Algunas prosas, se habla de "dioses" de modo generalizado sin que se puedan adscribir a una u otra religión: "Lo importante sería inventar un lenguaje azul. Que hable el que conozca a los dioses. Ese no soy yo. Y hablo" (Aub 1999: 58).

En este caso se está planteando (y rechazando) el poder de mediador entre el hombre y la divinidad que tiene el poeta, el autor.

Por otra parte, en "Manuscrito cuervo", ejemplo máximo de perspectivismo en el que un cuervo cuenta cómo ve la sociedad humana, se inventa una "religión-mitología" en la que "los que más mandan tampoco hacen exactamente lo que quieren, porque siempre dependen de una fuerza oscura inventada por ellos, la Burocracia. La Mentira y la Burocracia son los dioses de los externos" (Aub 1966: 182).

En un poema ${ }^{2}$ de Sala de Espera (vol. 5, p. 11), la referencia es también de tipo "aconfesional", acorde con la mentalidad del autor:

\footnotetext{
Tierra de nuestra sangre, repetida y hermosa, recostada en Europa, de Africa (sic) al Pirineo, bajo el sol de tus dioses obstinados y ardientes.
}

Del mismo talante (es decir, sin adscribirse a una mitología concreta) es la referencia que se hace en Viver de las aguas al entronque mítico de la fiesta popular: "Nadie, sin embargo, cuando llega la época de las fiestas de septiembre, deja de desear la aparición mítica del toro de fuego" (Aub 2000: 33).

\subsection{Mito y realidad en Max Aub}

Aunque es cierto que las referencias mitológicas descienden en la literatura más "sociopolítica", especialmente la literatura del exilio ${ }^{3}$, el carácter universal de los mitos hace que sirvan para dar cuenta de la realidad que rodea al autor. Buena prueba de ello es que, a propósito de la obra teatral El rapto de Europa ${ }^{4}$, con evidentes resonancias mitológicas, pero ambientada en Marsella en 1941, el autor afirmó: "Creo que no tengo todavía derecho a callar lo que ví [sic] para escribir lo que imagino", con lo que estaba aludiendo al realismo indudable de lo que allí se contaba. Por tanto, realidad y mito no son términos incompatibles. Además, desde el exilio, la referencia mítica contribuye a resaltar el entronque europeo y universal del drama (cfr. Lasso de la Vega 1964).

Así, sólo de modo parcial coincidimos con Lasso de la Vega cuando afirma, en relación con el teatro, que

\footnotetext{
el realismo, característica constante del modo de ser español, ha conferido tradicionalmente al teatro nacional español una calidad historicista y antimítica, poco propensa al uso de la apoyatura del mito clásico. El exacerbado individualismo hispánico inclina, por otra parte, mucho menos que en otros países al literato hacia la renovadora reelaboración de unos mismos temas o motivos. Si a ello se une la casi total ausencia de resonancias del mundo clásico en la vida cultural española de los últimos siglos, no podemos menos de extrañarnos al contemplar un cierto renacimiento del Mito clásico sobre la escena española contemporánea (1964: 444).
} 
Sin embargo, no es el momento de discutir en profundidad estas afirmaciones, puesto que, para bien o para mal, se ha prescindido en estas páginas del estudio de la obra teatral de Aub, aunque se haga referencia de modo esporádico a ella.

\subsection{Adaptación de los mitos}

El bagaje clásico que su educación y el mundo cultural que le rodea ofrecen a Aub es el que aflora en su obra de modo espontáneo, es decir, sin que haya, a mi parecer, un diálogo intertextual concreto con ningún autor grecolatino. Son imágenes y no textos los que se actualizan en la obra de Aub. Hay, no obstante, una excepción, que es el caso de "La confesión de Prometeo N.”, en el que la fuente directa es Esquilo. Merecería la pena detenerse en estos detalles, que marcan también una diferencia en las diferentes maneras de tratar el mito en nuestro autor.

Teniendo en cuenta el carácter atemporal que se le ha atribuido a los mitos clásicos, su aparición en la obra de este autor responde generalmente a un interés por actualizarlos y hacer valer su contenido universal, bien para entender el mundo exterior, bien para entenderse a sí mismo y al hombre. Estas referencias son, desde mi punto de vista, las más interesantes, como se verá a continuación. Hay, con todo, otra serie de casos en los que parece que el mito se presenta de forma menos "vivencial", más erudita, se podría decir; aunque "erudición" tal vez no sea el concepto que mejor se adapta a este uso. Se le puede llamar, por contraposición con respecto al mito actualizado, "el mito referido". A él se dedicará un apartado posterior.

\section{El mito clásico actualizado en Max Aub}

Se ha indicado ya repetidamente que el mito clásico se mantiene actual a través de los tiempos y que esa actualidad permanente es lo que, en última instancia, le confiere el clasicismo. En una cultura de larga tradición literaria, como es la occidental, se vuelven a contar una y otra vez las mismas historias, pero con tonos distintos (García Gual 1979: 11). "Porque el espíritu es llevado por su naturaleza a imitar los modelos que conoce, y mientras más alimentos reciba, más fuerzas poseerá" (Aub ${ }^{5}$ 1971: 11).

Este afán de recrear lo dicho por otros acerca a Max Aub a sus contemporáneos del 27; pero, en tanto el fondo mítico tiene validez atemporal, lo vincula con autores del pasado, y así, afirma el autor: "Me siento más cerca de un poeta del siglo V antes de Cristo, que de fray Augusto de la Inmaculada, que nació en 1922” (1963: 29). Es un mismo sustrato que se sustenta en la existencia de unos valores humanos universales.

Así, como indica Chirbes, es posible en este sentido rastrear las vinculaciones con autores anteriores, además de las filiaciones con el simbolismo y los Siglos de Oro españoles, ya citados. Afirma este autor que Aub

relee así a Galdós, recogiendo sus grandes temas -que algunos vienen desde muy lejos, desde la tragedia griega (...) y vuelve a hacerlos vivir a su manera: ahí recorriendo sus libros, vuelven a estar Climtemnestra o Edipo; vuelve el feroz Saturno para devorar a sus hijos, y unas veces se llama Alfaro, y otras Jiménez, o Mustieles, y con cada una de sus reencarnaciones, siempre nos deja la sospecha de que a lo mejor el progreso no es precisamente ineluctable (1999: 73). 
En la misma línea, con respecto a Ayala, que es casi coetáneo de Aub, afirma Amorós que

llega a una idea básica: todo se repite, todo es igual a lo que ya ha sido; aunque sea distinto por vivirlo personas diferentes. De aquí deriva una visión del mundo como encarnación repetida de los mitos clásicos (1972: 66)

A propósito de las figuras y los motivos míticos en Aub, se irá mostrando, de manera informal, cómo algunos de ellos presentan paralelismo con otras obras de la misma época, de manera que se demuestra que la aparición de la mitología clásica en nuestro autor no es, en modo alguno, un caso aislado, aunque muestre las peculiaridades propias de su estilo.

A lo largo de la obra de Aub, la actualización del mito va a ir tomando distintas formas, aunque, en contra de lo que se ha venido diciendo por parte de la crítica, se puede entender que el uso del mito tiene un fondo común en toda su trayectoria. Así, por ejemplo, para Soldevila,

\footnotetext{
Geografía es un texto narrativo típico de las tendencias europeas que en aquellos años (1921-25) Ortega y Gasset sintetizó poniéndolas bajo el marbete de "la deshumanización del arte" (1996: 14), y una de las características de esta literatura es la subversión parodiada de los grandes mitos, lo cual concuerda con la "visión deportiva de la vida (cfr. Soldevila 1996: 36)
}

que tuvieron los vanguardistas. Como se verá, la visión humorística se traduce en un erotismo festivo y hasta cierto punto despreocupación por el destino de las figuras que ahí aparecen. Con todo, una lectura atenta del texto podría revelar que la superficialidad del autor no es completa: tal vez no le preocupe el destino de los personajes, pero lo usa para mover a la reflexión sobre temas como el hogar, la ausencia o la seducción. Cierto es que por esa época Aub expresaba de este modo en un poema a Francis James su preocupación ante la "literatura deshumanizada" $"$

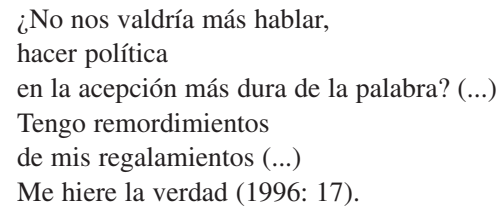

No obstante, del mismo modo que a esta obra, junto con Prehistoria, 1928, la presenta en Novelas escogidas (1970) bajo el epígrafe de "fábulas" (posiblemente — dice Soldevila - porque en ninguno de ellos se respetan las reglas que rigen la narración realista, y muy concretamente, la verosimilitud (1996: 10)); la inverosimilitud que le mueve a titularlas de ese modo está presente también en muchos cuentos posteriores. Así, por ejemplo, se ha dicho de Ciertos cuentos que en todos ellos "no se dan todavía las diferencias entre los procesos cosmológicos y los humanos" (Aub 2001: 17). Con todo, en ellos, cuando el mito se actualiza, el ambiente parece menos festivo y se alude más a los grandes temas humanos que presenta. A pesar de que Soldevila los clasifica en tema exótico-fantástico, mitológico actualizado e inspirado en instantáneas de la vida cotidiana (cfr. 1973: 169-73), incluyendo solamente en el segundo grupo (que es el que habría de interesarnos aquí) "Confesión de Prometeo N."7, son numerosas las referencias míticas en todo el volumen, como se puede comprobar en los apartados que siguen. De modo especial, se destaca el tema de la metamorfosis, que forma parte configuradora de algunos de ellos. 
En estos casos, el autor no considera su obra un juego, porque ha advertido (tal vez lo había sabido desde el principio, casi inconscientemente) que todo tiempo puede ser mítico, y especialmente el que le toca vivir. Como se verá a propósito de la figura de Prometeo, está en juego, ahora como entonces, la supervivencia de la especie, y por eso esta figura es plenamente actual.

Dice Aub en Crímenes ejemplares (donde la referencia a mitos clásicos es mínima y trivial) que "el hombre de nuestro tiempo sólo considera fracasos. El último gran mito cae ya, no de viejo, sino de potente. La grandeza humana sólo se mide por lo que pudo ser" (1972: 8).

Es tiempo, pues, de mitos caídos. Y por eso, quizás, hay una selección cuidadosa de las referencias míticas elegidas por Aub.

Finalmente, no se puede eludir una referencia al poema "Midas" que Max Aub pone en la pluma de Jean Louis Camard (1916-1942), uno de los autores de su Antología traduci$d a$. Refleja un procedimiento que el autor utiliza más de una vez (como se va a indicar en los apartados siguientes). Hay una referencia clásica que no se refleja de modo evidente: si no fuera por el título, tal vez no nos daríamos cuenta de que se habla del rey mitológico. Pero la idea, el fondo, queda ahí. En este poeta de la primera mitad del XX se retrata, como en todos los que componen la antología, el poeta Max Aub, pero no en su faceta de prestidigitador que cita a los clásicos para reírse de ellos ${ }^{8}$, sino en otra faceta en la que oye lo que pueden decirnos y enseñarnos:

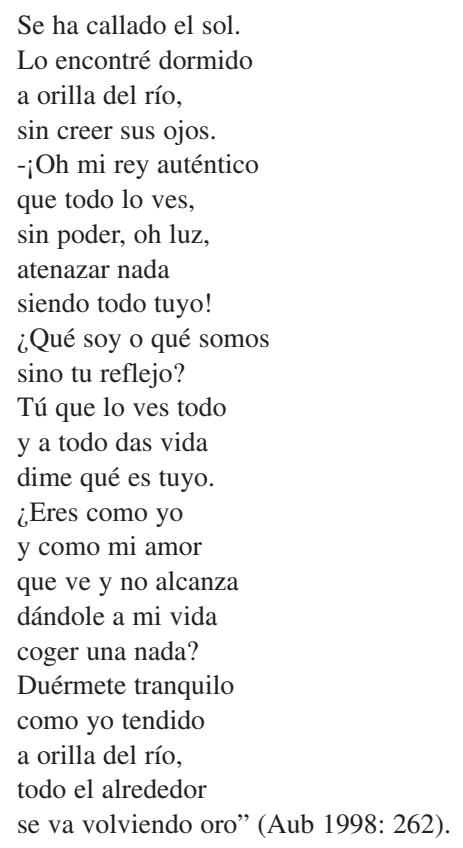

\subsection{Las figuras míticas}

Decía Ortega (1982: 113), a cuenta de la literatura "deshumanizada", que "los dioses del Olimpo son demasiado personas, demasiado reflexivos, preocupados, correctos; en suma, demasiado humanos para ser radicalmente divinos. Por eso, la religión dionisíaca invadió la 
Grecia con increíble rapidez: se vio en ella la posibilidad de contacto con una realidad más auténticamente trascendente, más genuinamente divina (...) La radical nulificación del hombre es el síntoma de toda grande y profunda — esto es, genuina - religión". En este caso, en cambio, es el carácter humano de las figuras míticas el que más interesa a Aub y por eso, incluso en las obras más "vanguardistas", se puede ver un fondo de humanidad, aunque, lógicamente, hay que matizar teniendo en cuenta la intención y el momento estético que afectan a cada una de las obras. Además, es muy interesante analizar el tipo de figuras que Aub elige para ponerles un rostro actual. Casi nunca son esos dioses de los que habla Ortega, frívolos y ocupados en intrigas, sino seres más cercanos, sobre todo identificados con el hombre que sufre.

Como se ha acotado para este trabajo de la obra narrativa breve (y no toda ella, por desgracia) de Max Aub, no se incluyen en los apartados siguientes la figura de Midas citada y otras que pueblan las novelas y la obra dramática de este autor. Así, por ejemplo, destaca el uso que hace de la figura de Narciso, que da nombre a una de sus obras teatrales ${ }^{9}$, si bien aparecerá también en alguno de sus cuentos. Como se ha comentado anteriormente, para Soldevila, Narciso simboliza uno de los dos polos entre los que se mueve la obra de Aub, y se opone a Teseo, que encarna la acción y la búsqueda, ya que Narciso es arquetipo de la autocontemplacion más pasiva, que en principio puede ser estéril, pero que puede entenderse también como un camino hacia el conocimiento del interior de uno mismo, y, por extensión, del interior del hombre.

Aunque no es fácil, las figuras míticas que aparecen en la narrativa breve de Aub pueden agruparse en diferentes grupos, y a partir de diferentes criterios de clasificación. Así, por ejemplo, y según lo que se ha estado comentando en el apartado anterior, se puede distinguir entre aquellas figuras de la etapa más "deshumanizada" del autor, que suponen hasta cierto punto un juego de ingenio, y aquellas figuras que reflejan el mundo en el que vive ese autor, con lo que suponen una actualización más viva y humana del mito. Sin embargo, a veces, una misma figura se repite en distintos momentos de la evolución de la narrativa de Aub, que, por otro lado, no están tan claramente delimitados como parece. Así, se irá comentando el diferente modo en que aparecen las figuras enumeradas.

Se ha optado, entonces, por otra clasificación, en la que se distingue entre monstruos, titanes, algún héroe y hombres. Nótese que, exceptuando el titán, no se eligen seres divinos; además este titán es Prometeo, que cae en desgracia entre los de su estirpe por amor al hombre. Es decir, como es esperable, las figuras míticas que se actualizan tienen un alto grado de humanidad. Por otro lado, tienen en común su participación en historias con fin trágico (a excepción tal vez de la sirena, aunque se matizará seguidamente esta afirmación), incluso, como es el caso de Hipólito, Fedra o Prometeo, son personajes de verdaderas tragedias de la Antigüedad (actualizadas en siglos posteriores). Prometeo, por ese amor especial al hombre que se ha indicado, se asemeja a los héroes en la presencia de un alma dividida, de una doble naturaleza, que también presenta la sirena (es la figura "monstruosa" que se estudia), una doble naturaleza que debió fascinar al Aub de las máscaras y los desdobles, un Aub que, por otro lado, tenía a jirones el espíritu como todos los trasterrados de su tiempo o tal vez más (por esa doble o triple patria que tuvo desde la infancia ${ }^{10}$ ).

Habiendo señalado, así, algunos rasgos generales que unifican a las figuras míticas cuya presencia se ha detectado en la obra analizada, se hará una reseña más detallada, aunque breve, en la que se comentarán las apariciones concretas de estas. 


\title{
3.1.1. Los monstruos: la sirena
}

La figura de la sirena, ser híbrido que participa de la naturaleza de mujer y de pez (en un principio se representaba con cuerpo de ave), aparece de forma evidente en el relato "Caja", perteneciente a la obra vanguardista de Aub y publicado en el número 58 de Alfar, de la Coruña, en $1926^{11}$. Frente a ella, Soldevila opone La sirena varada de Alejandro Casona como contrapunto de la deshumanización, plagada de figuras de estilo, de "Caja" (cfr. Soldevila 1999b). Con todo, la sirena de Aub, que sólo se nombra como tal en el último párrafo de la historia, es uno más de los personajes de este autor que encarnan el aislamiento, la insatisfacción y la frustración del hombre. Esa insatisfacción es representada también en Cernuda mediante la misma figura mítica, puesto que en este autor simboliza el deseo en su aspecto más doloroso que lleva a la autodestrucción, ya que su cuerpo anormal no le permite satisfacer los anhelos que su canto y la belleza de su rostro presentan: "Siempre recordaré la impresión angustiosa de esos labios fríos, viscosos y anhelantes. ¡Sí que era aljófar lo que asomaba en sus tristes ojitos de pez!" (Soldevila 1999b: 16).

A pesar de que gran parte del halo de fatalismo romántico que rodea a la figura de la sirena no proviene del mundo clásico sino de la imaginación de Hans Christian Andersen, en este caso se encuentra una novedad con respecto a la historia transmitida por la tradición, y es que esta sirena, atrapada en la caja registradora de una tienda, encuentra la felicidad al huir de ese lugar prosaico, lo cual es un motivo muy vanguardista:

\begin{abstract}
Tenía indudablemente ojos de pez, tan redonditos y asustados, además ¿quién no hubiese seguido inmediatamente la sugerencia al verla encerrada en aquel acuarium de cristal? (...) Y debía ser tan diferente la atmósfera allí dentro: aire rarificado, extraños presentimientos, y ella tan dulce, tan poca cosa, y la incurable melancolía del león del parque zoológico, que parecía flotar resignada y si pretendía usted, al entregar el talón, tocarle la mano, rehuía el contacto como las medusas un objeto extraño (Soldevila 1999b: 15).
\end{abstract}

La insatisfacción de la sirena de Aub no viene de la incompatibilidad de su naturaleza humana y animal, sino de que es un alma de pez en un cuerpo de mujer. Si el mar simboliza la libertad, Aub utiliza esta figura para hablarnos de la esclavitud del alma, tanto real como simbólica. En realidad, en este relato de lo que se habla es de una metamorfosis, por lo que tal vez sería más adecuado tratarlo en el apartado correspondiente ${ }^{12}$. Merece la pena reproducir el citado último párrafo del cuento:

\footnotetext{
Sirena de la caja, ya no tomarás resignada los dineros, que te fuistes [sic] con tus hermanas a bailarle el coro al viejo dios del mar. Cómo bailaba loca, nuevecita tu cola y cómo te revolvías ligera sin saber todavía la alegría de tu vida nueva, sirenita de la mar (en Soldevila 1999b: 16).
}

De la misma época, aproximadamente, es la aparición de la sirena en Geografía: "El viejo traje de sirena, todo pegado al cuerpo con la cola y los cabellos flotando" (Aub 1996: 107). Aquí parece que se refleja la misma angustia que en "Caja", puesto que estamos hablando de una mujer que desea huir del lugar en el que vive y que siente la llamada de lo éxotico, del mar, al fin y al cabo.

Las sirenas de los barcos hacían señales desesperadas a sus hermanas mitológicas que desde lejos -iqué bien las veía ella!- agitaban en prueba de cariño un blanco pañuelo de espuma (1996: 56). 
Aquí se utiliza como parte de la ambientación y se juega con la polisemia del término, lo que hace que la realidad y el mito se confundan, de la misma manera que los personajes son a la vez actuales y mitológicos.

Un juego de palabras mucho más sutil y menos vistoso, pero con la misma base de creación e incluso más capacidad evocadora, es el que encontramos en otro poema del citado Jean Louis Camard (una de las muchas caras con que se escuda Aub en Antología traducida): "Marsella Ocupada". Aunque no pertenezca a la narrativa breve, merece la pena reproducirlo aquí, especialmente porque sirve como contraste con los textos citados, ya que esta obra pertenece a una época posterior:

Jean Louis Camard (1916-1942), "Marsella Ocupada":

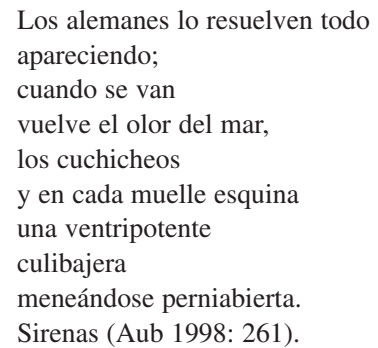

Este último "sirenas" puede referirse a las sirenas de los barcos, que a su vez evocan las sirenas que avisan de los bombardeos, como parte de la ambientación, pero también se puede entender que esas mujeres perniabiertas son sirenas: por su canto, o porque viven junto al mar, o porque añoran el mar, o porque son mujeres insatisfechas y atrapadas. Creo que puede verse todo mezclado, gracias a la capacidad evocadora del término ${ }^{13}$.

\subsubsection{Los titanes: Prometeo}

La figura de Prometeo puede considerarse de plena actualidad en nuestro siglo, especialmente en la primera mitad; esto se observa de manera especial en la "Confesión de Prometeo N.": "Como en el tiempo indefinido del mito, ahora, en la edad atómica, también está en juego la supervivencia" (Aub 2001a: 15).

$\mathrm{Y}$ es que, aunque esta figura ha sido actualizada en distintas ocasiones y con diferentes intenciones (por ejemplo, Tertuliano decía que Cristo era el "verus Prometeus"; Frankestein (nótese el contraste) es "el nuevo Prometeo") basándose en su humanidad y en su capacidad de sacrificio por amor al hombre, en esta época se "pone de moda". Exponentes de esta tendencia son, por ejemplo, el Prometeo de D’Ors, publicado en 1916, o la revista Prometeo. Revista social y literaria, fundada por Javier Gómez de la Serna en 1908, y que pretendía

\footnotetext{
que se eduquen los de arriba tanto como los de abajo y, sobre todo, la juventud que habrá de reemplazar a jueces, patronos, gobernantes y maestros [...] Queremos poner a su alcance el secreto arrebatado a la tierra, como el primer Prometeo les dio el fuego sabiendo que al poner en sus manos la luz ponía también el incendio.
}

El atractivo de dicha figura fue inevitable para esta generación, según el entender de Eloy Navarro (1994: 53-88), porque predicaba la rebelión sin límites, no una rebelión calculada y astuta como los ardides de Odiseo. 
Para Luis Díez del Corral (1974: 248-9), en este mito

falta por completo la noción de una justicia sobrehumana. La rebeldía titánica ha de concluir, de manera unilateral, en la restauración de un orden puramente humano, sin participación de instancias divinas.

Sin embargo, en Aub, el castigo proviene de los hombres y la amenaza no son los dioses sino las superpotencias. El paralelismo entre Rosenberg y Prometeo es evidente, puesto que el secreto de la bomba atómica, que el físico pasa a los soviéticos, es el fuego sobre el que se funda el poder de los nuevos dioses: los americanos. Aub se basa en la tragedia de Esquilo y toma sus mismas palabras en ocasiones; pero, teniendo en cuenta lo que se acaba de decir, hay un elemento que no es paralelo a la historia mítica y que debe ser tenido en cuenta: nuestro Prometeo no da el secreto "al común de los mortales" (sino a la U.R.S.S.), pero sí lo hace por amor a ellos ${ }^{14}$. Así, lo que pretende Prometeo N. es una suerte de equilibrio, porque los equilibrios son mejores que las omnipotencias y conceden un espacio de juego a los que sólo quieren ser hombres: el de la espera. En verdad, esa espera supone que el mundo todavía es joven y que no está cerrado (Aub 2001a: 15-6).

Sin embargo, es importante destacar que, en este cuento, las figuras míticas que se citan son muy variadas y abundantes y realmente se necesitaría un estudio más profundo y detallado que nos haría excedernos en el propósito de este trabajo y plantear otro independiente; de ahí que las notas que se han ofrecido se refieran sólo a la figura central de la narración.

\subsubsection{Los hombres}

\subsubsection{Hipólito, Fedra y Teseo}

La tragedia que viven Hipólito, Fedra y Teseo ha sido reelaborada desde la tradición grecolatina (Homero, Ovidio, Séneca, Esquilo, Eurípides) en numerosas ocasiones, que no es preciso enumerar aquí. Baste señalar que a principios del XX autores como D'Annunzio (1909) y Unamuno (1918) relataron los avatares de este malhadado trío. En el caso de Aub, el mito se subvierte de modo irónico en Geografía, si bien con ciertas modificaciones que a continuación se señalan. Así, en la obra de Aub, se incide sobre el aspecto erótico del mito, y el desenlace trágico sólo se sugiere (como indica Soldevila en la introducción a la edición de la Fundación Max Aub): "Sonreía Hipólito, con una rosa roja en la mano" (Aub 1996: 107); "la rosa roja en su mano como una copa; no vio ella otra cosa, y se fue agrandando, llenándolo todo, como luego su grito al coger desesperada el Trópico de Cáncer ¡ay, serpiente septentrional! y suicidarse con él” (Aub 1996: 108).

Además, Hipólito no muere "víctima de la credulidad de su padre y la perfidia de su criminal madrastra" (Ovidio 2001: 449), sino que el amor entre él y la mujer de su padre surge de modo espontáneo y natural. La relación con el mito clásico es voluntaria y explícita desde el punto en que se da el nombre de Hipólito al protagonista, si bien este nombre no aparece hasta bien entrado el relato: "No me dices nunca nada de Hipólito, de si te va a ver y es contigo amable y bueno como es él" (Aub 1996: 69).

Los otros nombres de los personajes se obvian, aunque el lector con un conocimiento medio de cultura clásica los deduzca. Así, por ejemplo, el viaje al Hades o a las Hespérides atribuidos a Teseo nos hacen que reconozcamos a este personaje mítico en la figura del 
Capitán, "vuelto en travesía directa de los Infiernos" (104), con "un galón, otro y otro aún, con hilos formando hojas y frutos de oro del jardín de las Hespérides" (107).

De cualquier modo, estas alusiones, casi juegos, forman parte del juego completo que supone escribir esta historia ambientándola en el mundo contemporáneo al escritor (y lector). Lo que nos interesa del Capitán es que, además de ser trasunto de Teseo, es un hombre viajero, de acción, que siempre busca el hogar. En este sentido, puede recordar también a Ulises, siempre con la añoranza del regreso a Ítaca, teniendo en cuenta que su mujer no es una Penélope que lo espere pacientemente alejando pretendientes.

\subsubsection{2. Ícaro}

En realidad, no hay referencia directa a Ícaro. Sin embargo, la referencia que se cita de la obra Crímenes ejemplares podría considerarse alusión a su caída del cielo, narrada por Ovidio (2001: 253-4):

\footnotetext{
Cuando el muchacho empezó a recrearse en su atrevido vuelo, abandonó a su guía, y, arrastrado por sus ansias de cielo, remontó el vuelo. La proximidad del abrasador sol ablanda la aromática cera que sujetaba las plumas (...) La cera se ha derretido; agita Ícaro sus brazos desnudos, y, desprovisto de alas, no puede asirse en el aire, y aquella boca que gritaba el nombre de su padre es engullida por las azuladas aguas, que de él tomaron nombre.
}

1972: 8)

La alusión a la que nos referimos es: “¿A quién no se le han caído hoy las alas?” (Aub

De cualquier modo, es discutible que se trate de una actualización del mito clásico, ya que también podría referirse a los ángeles caídos de la mitología cristiana. De cualquier modo, se alude a una caída espiritual que sólo de manera metafórica podría encarnarse en la figura de Ícaro, que se haría así el prototipo de hombre que muere por su ambición o descuido. Realmente, podría considerarse el símbolo de toda una época sin aspiraciones, donde, como Altazor, y como Ícaro, el hombre va cayendo al vacío.

\subsubsection{Leandro}

No hay tampoco una referencia explícita a Leandro. Sin embargo, la crítica ha señalado en el cuento "Uba Opa" ciertas reminiscencias de la mitología griega:

\footnotetext{
A pesar de todo lo dicho sobre el ambiente africano del cuento, éste tiene algunos elementos que lo relacionan con el mundo mítico griego. Las proezas acuáticas de Uba Opa recuerdan a las de Leandro cruzando a nado el Helesponto para ver a su amada Hero. También se puede relacionar con el mito de Narciso cuando Uba Opa ve su cuerpo mudado de color en la fuente: como el mítico personaje griego, al principio tampoco se reconoce (Aub 2001: 45).
}

Es cierto que el protagonista del cuento cruza el mar una y otra vez por amor: "UbaOpa no le hizo caso. Pensaba en su novia negra como la noche, en la isla verde, y seguía nadando" (Aub 2001: 135). 
Aunque Uba Opa no muere como Leandro, se puede decir que muere a su identidad de negro, que sufre una metamorfosis. De hecho, se repite dos veces la idea de que: "El mar es un círculo encantado y todo el que lo atraviesa, cambia o perece" (131).

Es más, se podría interpretar que este cuento es uno de los que tratan el tema de la metamorfosis (vid. infra) y que lo que une al protagonista y a Leandro es una idea de búsqueda que está presente en otros cuentos de la misma obra así como en otros motivos mitológicos (Ulises, Jasón, Teseo...). Se trata del motivo común del "viaje iniciático", que se repite en prácticamente todas las mitologías y todas las culturas.

\subsubsection{Narciso}

En cuanto a la relación con la figura de Narciso, que ocupó a Aub en la obra teatral a la que dio ese nombre, el párrafo al que hace referencia la crítica es el siguiente:

\footnotetext{
Llegó a una fuente, tuvo sed y quiso beber. Pero al inclinarse se le apareció un hombre blanco y se asustó. Se volvió rápidamente para ver quién era aquel ser extraño, pero estaba solo. Se volvió a inclinar para beber y de nuevo apareció el hombre blanco. Uba-Opa abrió la boca y el hombre blanco hizo lo mismo. Entonces Uba-Opa se dio cuenta de que aquella cara era la suya y se puso a llorar (Aub 2001: 135).
}

Como punto común, se encuentra el hecho de que al principio no se reconozcan en su reflejo y probablemente es cierto que Aub tenía presente la imagen en la que Narciso:

\footnotetext{
Se extasía ante sí mismo y sin moverse ni mudar el semblante permanece rígido como una estatua tallada en mármol de Paros (... ) No sabe qué es lo que ve, pero lo que ve le quema (...) Esa sombra que estás viendo es el reflejo de tu imagen. No tiene entidad propia; contigo vino y contigo permanece; y contigo se alejaría, si tú pudieras alejarte (Ovidio 2001: 133).
}

Con todo, hay que tener en cuenta algo que se ha dicho ya con antelación: los motivos míticos aparecen como asumidos plenamente por el autor, es decir, sin filiación directa con los textos clásicos. Por otro lado, la intención final es diferente, ya que el episodio de UbaOpa es una búsqueda de la propia identidad, mientras que en Narciso hay un castigo a la autocontemplación. De todos modos, es curioso cómo, del mismo modo que para los griegos esta historia explicaba el origen de la flor que se llama narciso, Aub la utiliza (la aventura de Uba-Opa) para dar una explicación mitológica de la crecida del Nilo, aunque (y eso es reseñable) lo hace en nota a pie de página:

\footnotetext{
En otros lugares de Sudán el cuento tiene este final: "Lloró tanto que allí se formó un lago. Cuando éste forzó las montañas, vino a río. Los blancos suelen llamarlo Nilo. Cada año Uba-Opa hace el viaje, cada año los peces le advierten de lo que va a pasar, cada año Uba-Opa no les hace caso, cada año Uba-Opa llora y cada año el río se desborda (Aub 2001: 135).
}

\subsection{Los motivos míticos}

\subsubsection{La Edad de Oro}

La Edad de Oro, en la que "la primavera era eterna, y plácidos céfiros de tibia brisa acariciaban las flores nacidas sin simiente; y también la tierra producía sin arar frutos" 
(Ovidio 2001: 70), no aparece sólo en Las Metamorfosis, sino en otras obras y autores, entre los que destaca Hesíodo, en Grecia, pero, convertido en lugar común, se encuentra a lo largo de todas las épocas en la literatura universal. No es lugar para mostrar ejemplos, aunque sí es preciso recordar que la existencia de un paraíso primigenio es parte integrante también de la mitología cristiana.

Como se indicó anteriormente, en Fábula verde, Aub recrea esta época idílica que en cuanto a paisaje se identifica además con la Arcadia (como se indica en el apartado correspondiente al vocabulario mítico a raíz del comentario del término "arcádico"). Esto está en relación con el mestizaje mítico del que se ha hablado.

\subsubsection{El ciclo anual}

En la explicación del ciclo de la primavera y el invierno, que supone una muerte y una resurrección de la naturaleza, los griegos recurrieron a la historia de Démeter, raptada por el dios del Hades. Aub sitúa a Margarita Claudia, protagonista de Fábula verde, "recluida en casa, bajo la tierra de los techos" (Aub 1993: 33) hasta que "la primavera brotó el mes de abril" (33).

Sin embargo, los rituales de primavera son patrimonio de casi todas las religiones, y tal vez no haya que buscar en estos ecos un origen directamente clásico ${ }^{15}$.

\subsubsection{Los Infiernos}

He aquí otro escenario común a distintas mitologías, por lo que no se puede decir que las referencias que a él se hacen sean herencia directa del clasicismo.

Con todo, hay indicios muy claros en algunas ocasiones de que se habla de los Infiernos clásicos. Así, por ejemplo, cuando se cuentan las aventuras del marinero de Geografía, trasunto de Teseo: "El tiempo vino a plegarse como un abanico el día en que el capitán llegaba, vuelto en travesía directa de los Infiernos" (Aub 1996: 104).

Eso no quiere decir que este "infierno", con ser trasunto de una historia literaria-mitológica, pierda su carácter simbólico o las connotaciones que la palabra ha adquirido en el uso habitual: el capitán ha estado en el país de los muertos y ese infierno no es otro que la separación de su hogar.

Además, cuando Max Aub se refiere al infierno como "lugar de los muertos", sin connotaciones negativas, la iconografía es la que muestran los escritos grecolatinos, heredada por la tradición occidental. Según esa iconografía, al Hades se accede cruzando el río del olvido (como plasma la expresión quevediana "desotra parte en la ribera", en el soneto "Amor constante más allá de la muerte"). Esa idea de que el infierno está al otro lado de un río la recoge Aub en distintas ocasiones. Así, por ejemplo, en "La lancha", se dice que "Más allá estaba Elanchove y los caballeritos de Lequitio, en el infierno" (Aub 2001a: 119).

El infierno es, literalmente, el "más allá", porque se refiere al otro lado del mar. Y esa visión del país de los muertos la utiliza el autor como si fuera la única existente, de manera que también aparece en boca de Aben Jaldún (otra de las máscaras de Aub), a pesar de que obviamente no es un escritor que pertenezca al mundo clásico ${ }^{16}$ : 
¡Ay! Tu sombra va a pasar a la otra orilla.

¡Oh, padre! ¿Por qué abandonas tu hogar, oh, padre? (Aub 1971: 23).

En "El silencio", no hay referencia explícita al reino de los muertos, pero "el otro lado" supone algo parecido para el protagonista del cuento, ya que su contacto con la hija que se marcha a esa otra orilla se hace cada vez más y más esporádico, hasta que llega a creer que ella ha muerto (es entonces cuando marcha a visitarla, pero sólo por una noche, porque ese no es el sitio de la vida para él): "No quería que se enterara de su decisión de pasar al otro lado, porque se había negado obstinadamente a hacerlo tantas veces como el joven se lo había propuesto" (2001a: 192).

\subsubsection{Las metamorfosis}

Este es el motivo mítico que mayor relevancia cobra en la narrativa breve de Max $\mathrm{Aub}^{17}$. Puede utilizarse como parte del "vocabulario mítico" que se tratará en el siguiente apartado, como ocurre en la preciosista Geografía: "La tarde se había metamorfoseado en plata, plata viva del cielo que olvidó al sol" (Aub 1996: 91).

Parece que el autor hace suya la afirmación de Ovidio (2001: 440-1) de que "todo se transforma (...) Todo fluye y la configuración de cada forma es pasajera (...) Nuestros cuerpos están en continua transformación".

Ya en su primer cuento, "Caja", que se ha comentado anteriormente, se recrea en describir la transformación de la muchacha de la tienda en sirena. El mar es el elemento transformador. Como se ha indicado, este motivo mítico se repite en la historia de "Uba-Opa", donde se dice que "el mar es un círculo encantado y todo el que lo atraviesa, cambia o perece" (Aub 2001a: 131).

En este cuento, el mar cambia la personalidad de Uba-Opa convirtiéndolo en blanco. A pesar de que el elemento transformador es el mismo, en el primer caso sirve para la realización del personaje mientras que en el segundo, bien al contrario, lo desarraiga, lo hace perder su idiosincrasia. En este sentido, en el primer caso se da una relación con la naturaleza que se va a ir repitiendo en otras obras. Así, en Fábula verde, aunque no podemos hablar de una transformación propiamente dicha, la protagonista se funde con la naturaleza en una relación tan íntima que, si bien ella no se llega a convertir en parte de la tierra, sí lo hace el fruto de su seno, que va a ser una manzana: "Se marchó corriendo a difuminarse en las hierbas"(Aub 1993: 32).

Ahora bien, esta fusión con la tierra está presente también en la obra posterior, ya que la metamorfosis en Aub es siempre un tira y afloja entre el hombre y la naturaleza, lo mismo que las metamorfosis ovidianas. Así, por ejemplo, en "El cojo", de 1937, se da esa misma relación íntima, si bien no llega a una transformación total:

La tierra sube por todas partes: en la hierba, en el árbol, en las piedras, y él se deja invadir sin resistencia notando tan sólo: ahora me llega a la cintura, ahora al corazón, me volveré tarumba cuando me llegue a la cabeza (Aub 1966: 68).

También hemos de notar aquí cómo es diferente la fusión de Fábula verde (o "Caja”), que parte de la afinidad de lo transformado y aquello en lo que se convierte, de esta que se 
acaba de citar, en la que la fusión es una especie de "castigo" o "revancha" de la naturaleza. En "La lancha", aparecen ambos tipos de transformación, y es el mar también el elemento donde tiene lugar la metamorfosis: por una parte, la madera de roble de la embarcación vuelve a su ser primigenio porque es su naturaleza (la transformación o metamorfosis a la que la ha sometido Erramón al hacer la barca es artificial, y por tanto debe ser subvertida): "Pero el casco seguía manando cada vez más abundantemente. Era ya un manantial de mil ojos. Y del mar parecían surgir ramas" (Aub 2001a: 125).

Por otra parte, la posible transformación del marinero en pulpo no parece ser fruto de la misma tendencia, ya que, aunque el pulpo es un animal marino y este hombre también, su fusión con el mar no es una "realización de su ser íntimo" sino que podría ser fruto de una venganza por parte del mundo natural: "Algún marinero habló de un pulpo enorme que apareció en aquel tiempo"(Aub 2001a: 125).

La transformación en árbol, que es todo un clásico de la literatura grecolatina, también tiene su parangón en la obra de Aub. En primer lugar, esta cita de "La falla" tiene un eco, tal vez un poco lejano, pero eco al fin y al cabo, de la famosa transformación de Dafne en laurel:

Las arterias y las venas, convertidas en yedras, le estrujaban el corazón, fatigando el pecho, avivándole el sentimiento (Aub 2001a: 165).

Apenas acabó su plegaria un pesado sopor invade sus miembros: una delgada corteza ciñe su tierno pecho, sus cabellos crecen como hojas, sus brazos como ramas, sus pies ha poco tan veloces se adhieren en raíces perezosas, en lugar del rostro está la copa: sólo la belleza queda en ella. Aun así la ama Febo, y colocando su diestra en el tronco, siente todavía palpitar su pecho debajo de la nueva corteza (Ovidio 2001: 183).

Sin embargo, en relación con esta cita, hay que hacer notar que la transformación del padre que está a punto de truncar la ilusión de su hijo por ver las fallas no es una transformación "real". De hecho, el carácter fantasioso de este cuento (dentro de la colección de los "ciertos cuentos" que se presentan como ciertos aunque no lo sean) radica en el hecho de que el tiempo hace un guiño que permite al padre llegar a tiempo para cumplir su promesa. Por el contrario, en "La ingratitud", donde hay otra metamorfosis de persona en árbol, sí que la transformación es real, y, como se ha indicado anteriormente a propósito de otros cambios de naturaleza que aparecen en Aub, acorde con el ser íntimo del personaje, porque se seca por dentro al sufrir el abandono de la hija y su soledad se mantiene incluso en su estado de árbol:

Seca, sin moverse, se convirtió en árbol; no era un árbol hermoso: la corteza arrugada, pocas hojas y éstas llenas de polvo; parecía una vieja ladeada en el borde del camino (...) Era un árbol que no tenía nada de particular, pero era el único que había hasta la hondonada. Todavía está allí (Aub 2001a: 201).

En este caso, parece que sí se está tomando la fuente clásica de modo directo, pues el texto recuerda de modo muy claro la metamorfosis de Filemón y Baucis, especialmente en la última oración, a pesar de que la historia de Aub es mucho más amarga.

Vio Baucis que a Filemón le salían hojas y el viejo Filemón que le salían a Baucis. Ya una copa crecía sobre ambos rostros y todavía se cruzaban palabras mientras aún podían, y al mismo tiempo se dijeron los dos "Adiós, mi amor" y al mismo tiempo el ramaje cubrió y ocultó sus labios. Todavía los nativos de Bitinia enseñan allí unos troncos vecinos, nacidos de sus dos cuerpos (Aub 2001a: 268). 
Por último, es muy interesante señalar cómo, por contraste con la historia anterior, la metamorfosis se utiliza también como un juego de humor, como sucede en "La verruga". A pesar de que pertenece a una etapa posterior, ese toque humorístico es muy propio de la literatura de vanguardias. En el caso de Aub, con todo, la ironía y el juego van a aparecer, con una finalidad crítica, como aquí se ve, a lo largo de toda la obra:

La piedra pómez, caballero, es de origen humano, la engendra el hombre; yo lo he visto, yo, personalmente, así como me está viendo a mí: cara a cara (Aub 2001a: 233).

¿De verdad no quiere ver a mi hijo convertido en una gran piedra pómez? (...) A veces, me pongo a pensar que quizá la luna es una gran verruga, una verruga ¿se da usted cuenta, caballero?, una verruga enfurecida (Aub 2001a: 236).

\subsection{El vocabulario mítico}

En este apartado, se recogen elementos léxicos que provienen de la mitología clásica pero que han pasado a formar parte de un vocabulario relativamente culto pero común. Cuando términos de este tipo aparecen en la literatura o la conversación normal, es probable que el hablante ni siquiera sea consciente de la filiación o el origen de estos. Con todo, no es posible prescindir de ellos en este estudio, dado que evidencian una influencia del mundo mitológico en la obra de Aub. Hay que hacer notar que aparecen en obras en las que no parece haber referencias "conscientes" a mitos, lo cual da prueba de lo arraigadas que se encuentran estas palabras en el léxico habitual del autor.

Así, por ejemplo, la prosa de "Luis A. Santullano" empieza de este modo: "Cierto aire arcádico. Un sub-paraíso. Como si las nubes o el cielo abierto sostuviesen un nacimiento" (Aub 1998b: vol. 4, p.12).

En realidad, la Arcadia no es un lugar mítico, aunque sí lo es su vinculación con la Edad de Oro y, en general, la asociación con una especie de locus amoenus, semejante al que presenta Fábula verde.

Ya se ha comentado con anterioridad la ambivalencia del término "sirenas", puesto que se puede jugar con sus dos significados, el primigenio, mítico, y el derivado, como nombre común. En este apartado, lo que interesa es el segundo uso; sin embargo, dado que las apariciones del término van acompañadas de personificación, no es tan fácil prescindir del recuerdo de su origen mítico. Así se indicó con respecto a "Marsella ocupada" y en la misma línea puede situarse "Enero sin nombre": "Cesan de gañir las sirenas"; "Otra vez las sirenas" (Aub 1998b: vol. 9, p. 13, 16).

Esa ambivalencia entre nombre común y propio es la misma que presentan nombres como "Océano". Cuando se utiliza con mayúscula se observa con mayor claridad el origen mítico del nombre, como ocurre en este caso (donde la referencia a Homero termina de situarnos en ese ámbito mitológico, que por otro lado llena toda la obra): “A veces le parecía, con Homero, que todo su espíritu estaba circundado por el Océano y otras dudaba de salidas infinitas e incomprensibles" (Aub 1996: 97).

Otras dos referencias al mito clásico ya lexicalizado y convertido en parte de la tradición lingüística (y, por tanto, no actualizado por el autor, salvo por el hecho de utilizar esas palabras) aparecen en Viver de las aguas, donde toda la fiesta, como se ha indicado en 
el apartado correspondiente, tiene carácter mítico. De ahí que se compare al toro con un animal mitológico de poder destructor: "Aparecen larguísimas sombras; a todo correr se empequeñecen, reduciéndose a la nada para volver a surgir, creciendo contrarias según la carrera del basilisco ${ }^{18 ", ~(A u b ~ 2000: ~ 32) . ~}$

La otra referencia clásica que se encuentra en este relato resulta ser un neologismo (al menos no está recogido en el Diccionario de María Moliner), con lo que este elemento del "vocabulario mítico" resulta de una mayor voluntad de actualización por parte del autor y podría incluirse, tal vez, en el apartado dedicado a figuras míticas y no a vocabulario mítico. A pesar de ello, se entiende fácilmente la posible lexicalización de "faetonte" como derivado de Faetón, que tomó el carro de su padre el Sol y se le desbocaron los caballos: "El faetonte es republicano y enemigo de las vaquillas, que tiene por espectáculo bárbaro y retrógrado, pero no falla el verlas" (Aub 2000: 29).

La referencia a Faetón se explica porque el autor se está refiriendo al conductor de autobús, con lo que el término queda como sinónimo de "guía, cochero", teniendo en cuenta además que él lleva "el ómnibus amarillo [...] a su trote mulero [...] del pueblo a la estación" (Aub 2000: 29).

Nótese la metáfora usada para la actualización mítica, ya que el autobús es como un carro y además es amarillo, como el carro del sol, que "de oro era el eje, de oro la lanza, de oro las llantas que recubrían las llantas" (Ovidio 2001: 96). Es un "guiño" al lector culto, que además encaja perfectamente en la forma de contar la historia, a pesar de que en ella las referencias clásicas sean mínimas.

\section{El mito clásico referido en Max Aub}

El siguiente apartado se ha concebido como contraste a las apariciones de los mitos clásicos que Aub utiliza para actualizarlos, es decir, para reflejar con ellos situaciones del mundo que lo rodeó. Aquí, en cambio, se van a exponer citas de contenido mitológico que parecen haber sido concebidas como tales, que adornan el discurso y dan prueba de la formación del autor, pero a las que no hay que buscar, en principio, más trascendencia.

Es interesante cómo son mucho menos numerosos los casos en los que el mito se utiliza de este modo, porque eso demuestra que en la obra de este autor, como en la de tantos otros del siglo $\mathrm{XX}$, sigue vivo y no es un reducto arqueológico.

Desde este punto de vista, se puede discutir la inclusión del poema siguiente (además, ya se ha comentado que la presente investigación se ceñiría, principalmente, a la prosa; pues bien, esta es una merecida excepción), que Aub pone en mano de su alter ego Luigi Coevo (1902-1920):

\footnotetext{
Todo lo hemos intentado De la mano de Prometeo, de la de Dédalo;

nada nos parece imposible bajo la égida de Hércules: si no somos dioses, merecemos serlo. ¿Qué hicieron ellos sino nacer? somos más, que habiendo sido paridos desnudos,
} 
podemos utilizar el fuego,

el aire y amaestrar la fuerza.

Somos más que los dioses,

podemos escupirles a la cara (1998a: 251).

A pesar de la acumulación de citas mitológicas, parece obvio que se usan las figuras como símbolo del poder humano (aunque ni Prometeo ni Hércules son humanos, sino un titán y un héroe, respectivamente) frente al divino. El propio Aub presenta a este autor napolitano, del que reproduce una anacreóntica, como autor de "quizá, más que ejercicios escolares" (1998a: 251). En este sentido, se puede decir que se están actualizando y no meramente citando. Con todo, se ha decidido incluirlo en este apartado porque Hércules, o Prometeo, o Dédalo, en este texto, no actúan, no "viven", por decirlo de algún modo, sino que son "nombrados" por la persona que habla.

También es una cita puesta en boca de personaje la de este culpable de uno de los Crímenes ejemplares, aunque en este caso se observa claramente que dicho hombre, que resulta ser un literato, está haciendo alarde de su saber clásico. Incluso el "dicen" es un indicio de que no cree en la realidad de lo que cuenta. Así, en este caso, y en consonancia con la ausencia de referencias míticas en esta obra, la cita es una mera forma de caracterizar a esta persona que habla:

Estaba leyéndole el segundo acto (...) Para ayudarle lo descabecé de un puñetazo; como dicen que Hércules mató bueyes. De pronto me salió de adentro esa fuerza desconocida. Me asombró (Aub 1972: 23).

En cambio, en "La falla" y "La verdadera historia de los peces blancos de Pátzcuaro", citados a continuación, el narrador, al hacer la referencia mítica, no se identifica con ningún personaje y, por tanto, se puede decir que el que habla está más cercano a Max Aub. En ambos casos, aunque se incluya en este apartado "menor" de referencias que nos parecen casi sin vida, hay que destacar que encajan bien en el talante de ambos cuentos; en el segundo de ellos, porque es en sí mismo un intento de explicación de la realidad, que, como ya se dijo, une distintas fuentes mitológicas. En esta cita el personaje mitológico tampoco actúa ni se actualiza. Parece un comentario de tipo filológico o literario:

\footnotetext{
Si un pez atravesaba su imagen reflejada tenían el convencimiento de que aquel animal era parte de su propio ser. Supongo que el mito de Narciso tiene cierta relación con esto (Aub 2001a: 173).
}

En el caso de "La falla", también hay una cierta intención revitalizadora al querer darle a las fiestas valencianas una realidad mítica. A pesar de ello, la referencia al robo del fuego por parte de Prometeo y el castigo subsiguiente al que fue sometido aparecen como un hecho pasado, aunque se den como reales (y sucedidos en un tiempo lejano):

\footnotetext{
Que un cartón, una tela, un papel, un madero puedan convertirse sin más en llama es un hecho tan extraordinario y fuera de lo racional (...) No hay transubstanciación más sorprendente (...) Sabían, Zeus y su cuerda, lo que hicieron con Prometeo, por cuanto les hurtó. Por eso el fuego siempre produce cierta suspensión del ánimo. Nuestros antepasados, por una razón u otra, tienen que ver con él (2001a: 162-3).
}

\section{Recapitulación y conclusiones}

En resumen, queda suficientemente demostrada la presencia del mito clásico en las obras analizadas y se hace constar cómo, en la mayor parte de las ocasiones, esta presencia 
muestra una voluntad de actualización que supone que los motivos míticos siguen vivos en nuestro siglo. En cuanto al resto de las apariciones, se trata de referencias de tipo culto que implican otro tipo de pervivencia, más anquilosada. Finalmente, también se han indicado elementos que prácticamente no suponen la intervención de la creatividad del autor sino que pertenecen a lo que se ha llamado en estas páginas "vocabulario mítico", ya que se trata de lexicalizaciones de términos pertenecientes a la mitología clásica. En realidad, es difícil adjudicar a uno u otro de estos apartados el tipo de referencia a los mitos que se hace en las obras analizadas.

Por otro lado, se advierte lo dicho en la introducción acerca del "talante mítico" de Aub: a la presencia de la mitología clásica se une la mitología cristiana, como en Fábula verde, o la mexicana, como en "La verdadera historia de los peces blancos de Pátzcuaro", en un mestizaje que se nos presenta como natural, de manera que a veces no se sabe bien a qué origen responde una referencia concreta y se llega a formar una "mitología maxaubiana", de carácter personal.

De ese carácter personal es fruto la selección que el autor hace de los motivos y figuras míticas que predominan en los cuentos. Así, teniendo en cuenta que uno de los temas principales de Aub es la soledad y el aislamiento que hacen infeliz al hombre, las figuras que actualiza son figuras que encarnan el sufrimiento y la frustración. En cuanto a los temas, se destaca el de la metamorfosis por ser el medio por el que sus personajes encuentran su verdadero ser, aunque a veces también se presente como una "revancha" ante su desarraigo o su rebeldía por parte de la naturaleza.

En suma, y teniendo en cuenta que el análisis presentado es necesariamente incompleto y superficial, Aub mantiene vivos los mitos clásicos en su narrativa breve. Sería muy interesante completar estas páginas con otras que estudiaran la presencia que esa mitología tiene en la narrativa novelesca o el drama del autor, para comprobar si las líneas aquí esbozadas encuentran eco en esos géneros. Pero eso deberá ser tratado en otra ocasión.

\section{Notas}

1. Del que se ha prescindido en este trabajo por las limitaciones en la selección arriba reseñadas.

2. Se titula "Paisaje de España". Aunque no pertenece estrictamente al corpus analizado, se considera pertinente incluirlo como ejemplo.

3. Por ejemplo, no se han encontrado referencias mitológicas en La verdadera historia de la muerte de Francisco Franco y apenas ninguna en los textos de la revista Sala de Espera.

4. Se prescinde de esta obra en el estudio que sigue por pertenecer al género dramático.

5. En boca de Aben Jaldún.

6. De la que renegó de modo más claro con la parodia y destrucción que planteaba en la figura de Luis Álvarez Petreña.

7. Que, además, según este autor, forma un grupo aparte narrativamente, pues "se abandonan casi totalmente - a pesar de su inspiración en lo clásico — las maneras tradicionalmente narrativas y se acude a la transgresión mediante la utilización de la confesión” (Soldevila 2001:33). 
8. Hay que insistir en que esa faceta nunca fue "pura", al menos desde mi punto de vista.

9. También aparece en otras obras de autores de la época; así, por ejemplo, en Canciones (1921-24), de Lorca, que corresponde, en "Tres retratos", a Debussy.

10. Aunque se sentía valenciano, porque, afirmaba, "uno es de donde se hace el bachillerato".

11. Cito por Soldevila 1999a: 15-16.

12. Así narra Ovidio la transformación de las Aqueloides en Sirenas (2001:187): "Luego que la buscasteis [a Proserpina] en vano por el mundo entero, entonces, para que los mares conocieran vuestro afán, deseasteis poder posaros sobre las olas con los remos de unas alas, y encontrasteis dioses propicios y visteis cómo de repente vuestro cuerpo se cubría de un dorado plumaje. Pero para que aquel canto, destinado al deleite de los oídos, y tan grandes dotes vocales no perdieran el uso del habla, subsistieron vuestras caras de doncella y la voz humana". Nótese cómo no se hace referencia a su función de "arruinadoras de hombres", que parte de la Odisea, ni la doble naturaleza a la que se ha hecho alusión en el texto, si bien es posible deducir que la tristeza es uno de los rasgos de estos seres monstruosos, ya que la metamorfosis surge a partir de la búsqueda infructuosa de la compañera perdida.

13. Los dos primeros significados que da María Moliner (edición electrónica) son: 1. (*mitología). Ser con la mitad superior del cuerpo de mujer y la mitad inferior de pez o de ave, de los que habitaban las rocas marinas y atraían a los escollos a los navegantes con la dulzura de su canto. 2. Instrumento que produce un *sonido semejante al de una trompa, generalmente por el escape intermitente de aire comprimido a través de un obturador giratorio; como las que se emplean para avisar la entrada y salida en las fábricas o, en tiempo de guerra, para dar la señal de alarma ante la proximidad de un ataque aéreo.

14. Dice Alborg que Prometeo N. "no obra por razones políticas, sino por amor al hombre genérico" (1962: 121). "En eso consiste, precisamente, el idealismo de Max Aub" (Aub 2001a: 95).

15. De todos modos, dada la formación cultural de Aub (y de Occidente), hay bastantes probabilidades de que así sea.

16. Aunque también se evidencia con esto la extensión de esta visión del infierno, incluso más allá de la mitología clásica.

17. De manera especial en Ciertos cuentos; de ahí que se pueda disentir de la clasificación de Soldevila en la que sólo se indicaba como de tema mítico "Confesión de Prometeo N.". De todos modos, a la crítica no se le ha pasado por alto esta circunstancia. Así, al comentar "La lancha", se afirma que "Erramón Churrimendi ha sufrido una metamorfosis, como la de Dafne al ser perseguida por Apolo. Esta transformación conecta el cuento con una tendencia generalizada en la narrativa aubiana, pues no difería de las que afectan a los personajes principales de cuentos o fábulas que el autor escribió antes de la guerra, como "Caja" o Fábula verde, o algunas que están presentes en cuentos de la presente colección, como puede verse en "La ingratitud"” (2001a: 39).

18. "Basilisco" es una palabra de origen latino (< basiliscus), que a su vez viene del griego basiliscos (diminutivo de basileus, "rey"), y María Moliner lo define como "animal fabuloso al que se atribuía que mataba con la mirada".

\section{Bibliografía}

Alonso, Cecilio (ed.). 1996. Actas del Congreso Internacional "Max Aub y el laberinto espanol”. Valencia: Ayuntamiento de Valencia. 
Amorós, Andrés. 1972. La novela intelectual de Ramón Pérez de Ayala. Madrid: Gredos.

Aub, Max. 1972. Crímenes ejemplares. Barcelona: Lumen.

1993. Fábula verde. Segorbe: Ayuntamiento de Segorbe y Universidad de Córdoba.

1996. Geografía. Prehistoria, 1928. Segorbe: Ayuntamiento de Segorbe. Edición crítica, prefacio y notas de Ignacio Soldevila Durante.

1998a. Antología traducida. Segorbe: Fundación Max Aub y Universidad Jaume I. Introducción, edición y notas de Pasqual Mas i Usó.

1998b. Sala de espera. Vols. 1 a 10. Segorbe: Fundación Max Aub.

1999. Algunas prosas. Segorbe: Fundación Max Aub y Dirección General del Libro y Coordinación Bibliotecaria de la Generalidad Valenciana.

2000. Viver de las aguas. Segorbe: Excmo. Ayuntamiento de Viver, Fundación Max Aub y Biblioteca Valenciana.

2001a. Ciertos cuentos. Segorbe: Fundación Max Aub y Dirección General del Libro y Coordinación Bibliotecaria de la Generalidad Valenciana. Edición, introducción y notas de Jesús S. Carrera, Laura Gadea, Miguel Á. González, Ana I. Llorente y Álvaro Romero.

2001b. La verdadera historia de la muerte de Francisco Franco. Segorbe: Fundación Max Aub.

Carreño, Antonio. 1996. "Hacia una morfología de personae y máscaras: el caso Max Aub". En Alonso (ed.), 137-155.

Chirbes, Rafael. 1999. "El Yo Culpable”. En Soldevila y Fernández (eds.), 55-76.

Díez del Corral, Luis. 1974. La función del mito clásico en la literatura contemporánea. Madrid: Gredos.

Durán, Manuel. 1996. "Humor, indignación: dos extremos en la obra de Max Aub”. En Alonso (ed.), 123-135.

García Gual, Carlos. 1979. Prometeo: mito y tragedia. Madrid: Hiperión.

Gómez Canseco, Luis (ed.). 1994. Las formas del mito en las literaturas hispánicas del siglo $X X$. Huelva: Universidad de Huelva. 
Lasso de la Vega, J. S. 1964. "El mito clásico en la literatura española contemporánea”. Actas del II Congreso Español de EECC, 405-466.

Martínez Latre, Mª Pilar. 1996. "Estrategias narrativas vanguardistas en la prosa lírica de Max Aub”. En Alonso (ed.), 394-406.

Navarro, Eloy. 1994. "El mito de Prometeo en la generación de 1914”. En Gómez Canseco (ed.), 53-88.

Ortega y Gasset, J. 1982. Ideas sobre el teatro y la novela. Madrid: Alianza.

Ovidio, P. 2001. Metamorfosis. Madrid: Alianza.

Soldevila Durante, Ignacio. 1973. La obra narrativa de Max Aub (1929-1969). Madrid: Gredos. 1996. “Max Aub: cara y cruz de una creación literaria”. En Alonso (ed.), 41-54. 1999b. "De la literatura deshumanizada a la literatura responsabilizada: un diálogo intertextual entre Aub y Casona". En Soldevila y Fernández (eds.), 1-16.

Soldevila Durante, Ignacio y Dolores Fernández. 1999a. Max Aub: veinticinco años después. Madrid: Editorial Complutense. 